\title{
Effect of Sodium Carbonate Concentrations on the Formation and Mechanism of Regenerated Silk Fibroin Nanofibers by Electrospinning
}

\author{
Hao Dou and Baoqi Zuo \\ National Engineering Laboratory for Modern Silk, College of Textile and Clothing Engineering, Soochow University, \\ No. 199 Ren-ai Road, Suzhou 215123, China
}

Correspondence should be addressed to Baoqi Zuo; bqzuo@suda.edu.cn

Received 10 April 2014; Accepted 27 June 2014; Published 16 July 2014

Academic Editor: Xuedong Bai

Copyright (C) 2014 H. Dou and B. Zuo. This is an open access article distributed under the Creative Commons Attribution License, which permits unrestricted use, distribution, and reproduction in any medium, provided the original work is properly cited.

Degumming is the first process for the preparation of all silk-based products. In this paper, effect of sodium carbonate concentrations for silk degumming on the formation of electrospun silk fibroin nanofibers was investigated and the reason for the silk electrospinning process was explained for the first time by differences from the microstructure of regenerated silk fibroin. With increasing the sodium carbonate concentration, microstructure both in the aqueous solutions and in the electrospinning solutions transformed from nanofibrils to nanoparticles, leading to obvious changes on rheological property; electrospinning solutions with nanofibrils behaved like the native silk dope and owned remarkably higher viscosity than the solutions with nanoparticles showing very low viscosity. More interestingly, nanofibrils favored the formation of silk nanofibers with ease, and even nanofibers could be electrospun at concentration $2 \%$. However, nanoparticles were completely unable to generate nanofibers at high spinning concentration $8 \%$. Importance of sodium carbonate concentrations is heavily emphasized for impacting the microstructure types and further influencing the electrospinning performance of regenerated silk. Hence, sodium carbonate concentrations provide a controllable choice for the preparation of silk-based electrospun biomaterials with desired properties.

\section{Introduction}

Silk is well known as a natural material which has been widely used in the traditional textile industry for its pearly luster and outstanding mechanical properties [1]. Consisting of repetitive protein sequences, silk represents excellent cytocompatibility, low inflammability, good biocompatibility, and biodegradability. Hence, much attention has been paid to the extended use of silk in biomedical applications as a regenerated biomaterial in various kinds of forms, such as powders, gels, sponges, films, and fibers [2].

Recently, electrospinning has been extensively explored as a simple and versatile technique that can directly produce natural or synthetic polymer nanofibers for applications such as high performance filters, biomaterial scaffolds for cell growth, vascular grafts, wound dressings, and drug delivery systems [3-6]. Due to the high surface area and highly porous three-dimensional structure, biocompatible materials with nanoscale diameters are being developed for high-density cell and tissue cultures. As an ideal candidate of tissue scaffolds with several distinctive biological properties, nonwoven silk-based nanofibers prepared by electrospinning mimic the structure and biological function of native extracellular matrix (ECM) proteins, which provide mechanical support and regulate cell activities $[7,8]$.

Since morphology and diameter distribution of silk fibroin (SF) nanofibers are connected with the process parameters of electrospinning, which include solution properties, nozzle-collector distance, flow rate, electric field strength, and environmental conditions $[9,10]$, some researchers have investigated the electrospun nanofibers prepared from regenerated SF. For example, Jin et al. developed an all-aqueous process for silk electrospinning in combination with $\mathrm{PEO}$ which enhanced the viscosity of the spinning solution [11]. Park et al. introduced the blend with chitosan to improve the viscosity and conductivity of the SF solution, which 
provide benefits of electrospinnability [12]. On the other hand, more studies on effects of solvent types including water, hexafluoroacetone, hexafluoroisopropanol, and formic acid (FA) were also under consideration [13-15]. Furthermore, Sukigara et al. systematically reported the optimum processing parameters essential to generate silk nanofibers reproducibly and continuously by electrospinning, which established theoretical and experimental foundations for the relationships between electrospinning parameters and fiber diameters [16-18]. However, as a key parameter which may determine the performance of silk electrospinning, the structure of silk materials itself especially its microstructure is not received sufficient recognition [19].

Silk in its natural form is composed of a filament core protein, silk fibroin, and a glue-like coating consisting of sericin proteins [20]. In order to obtain the silk-based biomaterials, the cocoon has to undergo the harsh thermochemical treatment which can result in changes in the molecular weight, mechanical property, and degradation behavior of origin silk $[21,22]$. Because of this reason, the effect of varied degumming conditions on the silk fibroin materials has been investigated. Jiang et al. clearly demonstrated the difference of five degumming methods based on the tensile behavior, mechanical properties, morphology, and fractography of cocoon silk [23]. Wray et al. provided detailed characterization of silk fibroin degumming, indicating significant effect of degumming time on cell viability and the ability to form three-dimensional porous scaffolds from silk [24]. Yamada et al. found that sericin was removed by the treatment for only $5 \mathrm{~min}$ at $100^{\circ} \mathrm{C}$ without damage to fibroin, whereas prolonged heating degraded the silk fibroin heavy chain by SDS-PAGE analysis [25]. In addition, a few previous studies have examined the effect of degumming on the electrospinning of silk. Zarkoob et al. directly dissolved degummed silk to a concentration of $0.74 \%$ in hexafluoro-2propanol for 5 months and surprisingly fabricated nanoscale silk fibers with average diameter $25 \mathrm{~nm}$ [26]. Recently, the effect of residual sericin on the electrospinning performance of silk was considered by Ko et al. [27]. The authors suggested that sericin contents are relevant to the molecular weight distribution and solution properties, which have influence on the electrospinning results. However, documents on the intrinsic differences from microstructure of the regenerated silk itself disrupted by degumming are still necessary.

In this paper, raw silk was degummed with a series of sodium carbonate $\left(\mathrm{Na}_{2} \mathrm{CO}_{3}\right)$ concentrations while other experimental conditions were kept constant, aiming to further examine the effect of $\mathrm{Na}_{2} \mathrm{CO}_{3}$ concentrations on the formation of regenerated silk fibroin nanofibers by electrospinning. First, the discrepancy in the SF/FA spinning solution properties were elucidated based on the rheology test and then the morphological characterization of electrospun SF nanofibers was conducted by SEM. Furthermore, subsequent experiment was designed for confirmation and study on the microstructural changes of regenerated SF solutions was investigated using SEM and AFM. Finally, an understanding mechanism responsible for the relationship between $\mathrm{Na}_{2} \mathrm{CO}_{3}$ concentrations and electrospinnability was proposed from the aspect of the microstructural variations of silk itself that resulted from the different $\mathrm{Na}_{2} \mathrm{CO}_{3}$ concentrations.

\section{Experimental}

2.1. Preparation of Regenerated Silk Fibroin. Grade 6A raw silk with a 20/22 denier was used for this research (produced in Huzhou City, Zhejiang Province, China). In order to study the influence of $\mathrm{Na}_{2} \mathrm{CO}_{3}$ concentrations on the electrospinning performance, four samples of raw silk were, respectively, degummed three times with $5 \%, 0.5 \%, 0.05 \%$, and $0.005 \%$ wt $\mathrm{Na}_{2} \mathrm{CO}_{3}$ solutions in boiling deionized water for $30 \mathrm{~min}$ (all material-to-liquor ratio was 1:40), and then washed with warm distilled water carefully. The weight loss of raw silks was $68.8 \pm 7.8 \%, 32.6 \pm 1.5 \%, 29.2 \pm 0.9 \%$, and $27.9 \pm$ $0.6 \%$, respectively, determined by weighing the remaining solid after drying. The weight losses were calculated using the following equation: weight loss $(\%)=(1-$ dry mass of degummed silk/dry mass of raw silk) $\times 100$. All tests were performed in triplicate.

Degummed silks above were dissolved in $9.3 \mathrm{~mol} / \mathrm{L}$ $\mathrm{LiBr}$ solution. After dialysis in cellulose tubular membrane (molecular weight cutoff $=8000 \sim 14000$, Sigma, USA) against distilled water for 3 days and filtration, the silk fibroin (SF) solutions were, respectively, cast on polystyrene Petri dishes to prepare regenerated SF films at room temperature.

2.2. Electrospinning. SF spinning solutions from four different degummed silks were prepared by dissolving the above regenerated SF films in 98\% formic acid (FA) (Suzhou Yacoo Corporation, AR, China) for $3 \mathrm{~h}$. Concentrations of four SF solutions for electrospinning were all $8 \%$ by weight at the first time. After that, concentrations of SF/FA solutions from $0.005 \% \mathrm{Na}_{2} \mathrm{CO}_{3}$ concentration were prepared at $1 \%, 2 \%, 3 \%$, and $6 \%$, respectively, trying to obtain nanofibers for further experimental confirmation.

In the electrospinning process, a high electric potential was applied to a droplet of SF solution at the tip $(0.8 \mathrm{~mm}$ in inner diameter) of a syringe needle. The electrospun nanofibers were collected on flat aluminum foil which was placed at a distance of $12 \mathrm{~cm}$ from the syringe tip. A constant volume flow rate of $0.3 \mathrm{~mL} / \mathrm{h}$ was maintained using a syringe pump (Baoding Longer Precision Pump Co., Ltd., China) and a voltage of $14 \mathrm{kV}$ was applied to the collecting target by a high voltage power supply (Tianjin Dongwen High-Voltage Power Supply Co., Ltd., China).

\subsection{Characterization}

2.3.1. Rheological Analysis. Rheological studies were run on a Rheometer (TA Instruments, AR2000, America) with a $40 \mathrm{~mm}$ cone plate $\left(\mathrm{Ti}, 40 / 2^{\circ}\right.$ ). The normal force applied on the sample during lowering of the top plate was limited to $0.1 \mathrm{~N}$. The shear rate was linearly increased from 0.1 to $5000 \mathrm{1} / \mathrm{s}$ at $25^{\circ} \mathrm{C}$.

2.3.2. Scanning Electron Microscopy. In order to observe the microstructural morphology of the aqueous SF solutions, 
samples derived from different $\mathrm{Na}_{2} \mathrm{CO}_{3}$ concentrations were diluted $1: 10^{5}$ with deionized water and then $2 \mu \mathrm{L}$ of the diluted SF aqueous solutions were dropped onto freshly cleaved $5 \times 5 \mathrm{~mm}^{2}$ mica surfaces, respectively. After drying under vacuum, samples above were mounted on a copper plate and sputter-coated for $90 \mathrm{~s}$ with gold layer $20-30 \mathrm{~nm}$ thick prior to imaging (Hitachi S-4800, Japan). The morphology of electrospun SF nanofibers was also observed using an SEM at $20^{\circ} \mathrm{C}, 60 \mathrm{RH}$. The diameters of the fibers were measured from randomly collected SEM images using the ImageJ software and expressed as mean \pm standard deviation (SD).

2.3.3. Atomic Force Microscopy. To investigate the microstructure of samples for AFM imaging, a SF/FA solution of $0.0005 \mathrm{wt} \%$ was prepared by diluting the four SF/FA solutions above with formic acid; then $2 \mu \mathrm{L}$ of the diluted SF/FA solution was dropped onto freshly cleaved $5 \times 5 \mathrm{~mm}^{2}$ mica surfaces, respectively. The morphology of silk fibroin in formic acid was observed by AFM (Veeco, Nanoscope V) in air. A $225 \mu \mathrm{m}$ long silicon cantilever with a spring constant of $3 \mathrm{~N} / \mathrm{m}$ was used in tapping mode at $0.5-1 \mathrm{~Hz}$ scan rate [19].

\section{Results}

3.1. Effect of $\mathrm{Na}_{2} \mathrm{CO}_{3}$ Concentrations on the Rheological Property of SF/FA Electrospinning Solutions. In electrospinning process, viscosity of spinning solutions plays a significant role in not only understanding the structure and physical properties in the solution state [20] but also determining the morphology and size of the electrospun products $[5,8-10,16]$. In this experiment, viscosity measurements over a range of shear rates of the SF/FA solutions at $8 \%$ concentration were shown in Figure 1. All four curves firstly exhibited shearthickening behavior and then rapidly followed by shearthinning behavior at low shear rates $\left(<0.2 \mathrm{~s}^{-1}\right)$. However, the trend became divided with the increase of shear rates. When $\mathrm{Na}_{2} \mathrm{CO}_{3}$ concentrations were $5 \%$ and $0.5 \%$, the solutions behaved as a shear-independent Newtonian flow with relatively low viscosity (Figures $1(\mathrm{a})$ and $1(\mathrm{~b})$ ) while the viscosityshear-rate profiles from the $\mathrm{Na}_{2} \mathrm{CO}_{3}$ concentrations $0.05 \%$ and $0.005 \%$ indicated that shear thinning phenomenon continuously took place with increasing the shear rate similar to the behavior of the native silk dope [28, 29], showing obvious higher viscosities (Figures 1(c) and 1(d)). All in all, the viscosity of the regenerated SF/FA solution decreased with the increasing $\mathrm{Na}_{2} \mathrm{CO}_{3}$ concentrations.

\subsection{Effect of $\mathrm{Na}_{2} \mathrm{CO}_{3}$ Concentrations on the Morphology of} Electrospun Silk Nanofibers. Many reports have emphasized the significant effect of the solution viscosity on the electrospinning process $[5,7,9-11,16]$. Corresponding to the variation of spinning solution viscosities above, different morphologies and sizes of electrospun silk nanofibers were clearly presented in Figure 2 and Table 1 . At a $\mathrm{Na}_{2} \mathrm{CO}_{3}$ concentration of $5 \%$, droplets or beaded particles instead of the fibrous structure were found in great numbers with round shape (Figure $2(\mathrm{a})$ ). When $\mathrm{Na}_{2} \mathrm{CO}_{3}$ concentrations

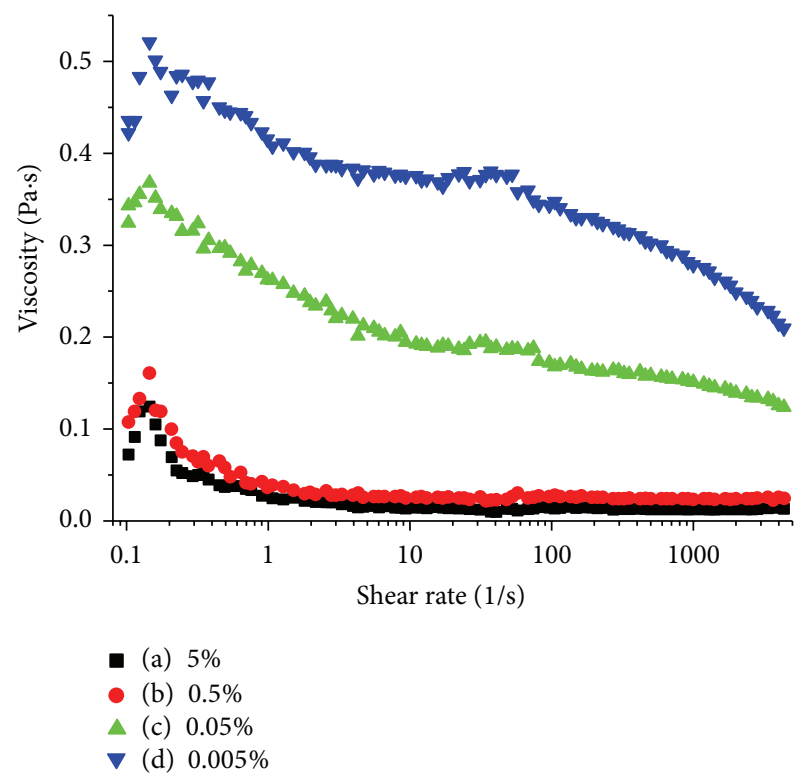

FIGURE 1: Relationship between the shear viscosity and shear rate of the $8 \% \mathrm{SF} / \mathrm{FA}$ electrospinning solutions prepared from different $\mathrm{Na}_{2} \mathrm{CO}_{3}$ concentrations: (a) $5 \%$, (b) $0.5 \%$, (c) $0.05 \%$, and (d) $0.005 \%$.

TABLE 1: Size data of electrospun silk nanofibers from $8 \%$ SF/FA solutions prepared from different $\mathrm{Na}_{2} \mathrm{CO}_{3}$ conditions: (a) $5 \%$, (b) $0.5 \%$, (c) $0.05 \%$, and (d) $0.005 \%$.

\begin{tabular}{lcc}
\hline Samples & Average diameter $(\mathrm{nm})$ & Standard deviation $(\mathrm{nm})$ \\
\hline (a) & 518.8 (particles) & 320.5 \\
(b) & 1222.4 (particles) & 781.7 \\
(c) & 355.6 (fibers) & 81.0 \\
(d) & 1341.2 (fibers) & 261.8 \\
\hline
\end{tabular}

were reduced to $0.5 \%$, droplets or fragments were stretched into irregular shape since the viscoelastic forces were still not sufficient to overcome the repulsive forces of charge (Figure 2(b)). However, bead defects suddenly disappeared and formation of fine and rod-like nanofibers with smooth surface occurred at the $\mathrm{Na}_{2} \mathrm{CO}_{3}$ concentration of $0.05 \%$ with diameter about $355.6 \pm 81.0 \mathrm{~nm}$ (Figure 2(c)). In addition, continuous electrospun fibers with a sharp increase of diameter to $1341.2 \pm 261.8 \mathrm{~nm}$ were obtained as a decrease of $\mathrm{Na}_{2} \mathrm{CO}_{3}$ concentration (Figure 2(d)), revealing a remarkable discrepancy in the morphologies and sizes of outcomes that strongly depends on the $\mathrm{Na}_{2} \mathrm{CO}_{3}$ concentrations.

Although the silk fibroin solution is required to have a critical concentration to ensure the formation of beadless continuous fibers, electrospun fibers with micron diameter at $8 \%$ were easily formed where almost no microfibers were found by other papers $[8,9,16]$. This surprising experimental observation promoted us to study further and several low concentrations were designed for electrospinning.

3.3. Effect of Solution Concentrations on the Rheological Property of SF/FA Electrospinning Solutions from 0.005\% $\mathrm{Na}_{2} \mathrm{CO}_{3}$ Concentration and on the Morphology of Electrospun 


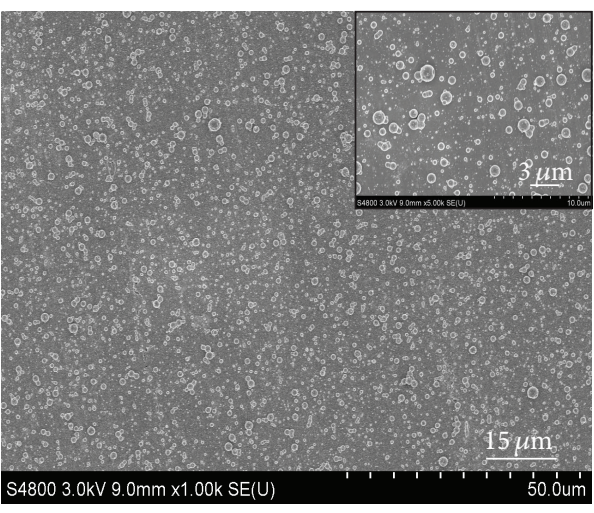

(a)

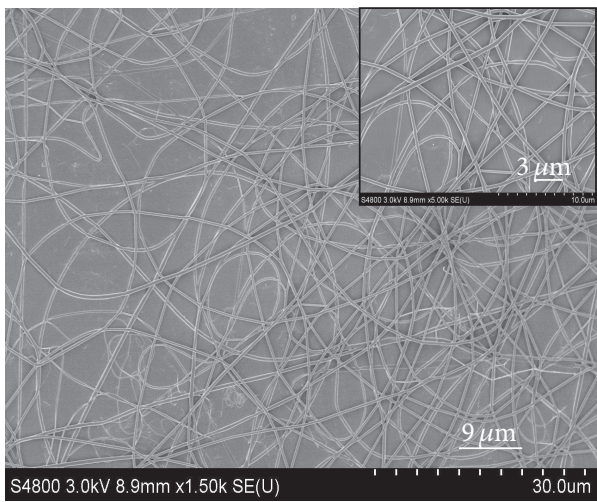

(c)

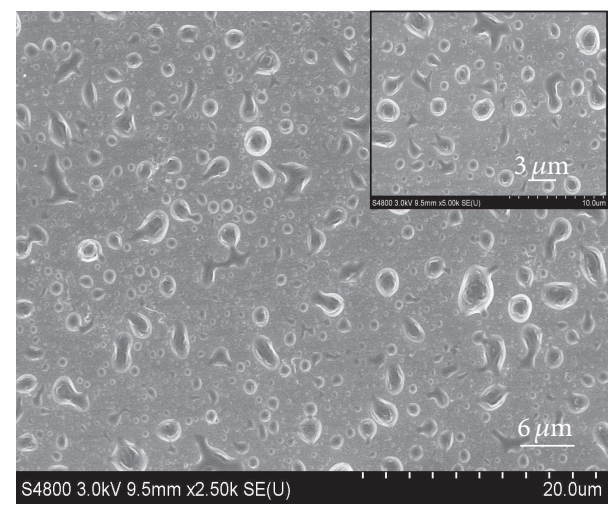

(b)

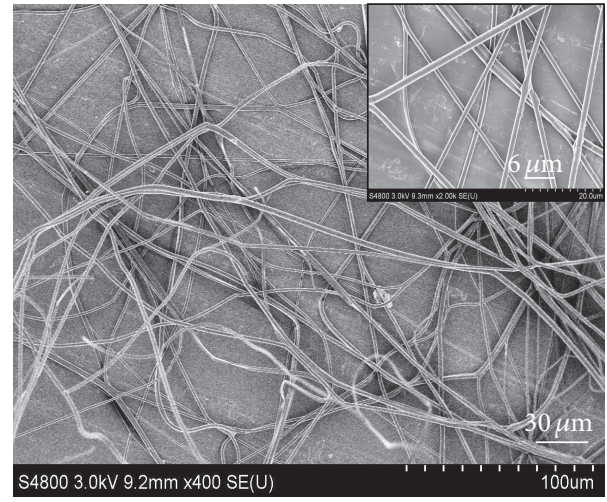

(d)

FIGURE 2: SEM images of electrospun silk nanofibers from $8 \%$ SF/FA solutions prepared from different $\mathrm{Na}_{2} \mathrm{CO}_{3}$ concentrations: (a) $5 \%$, (b) $0.5 \%$, (c) $0.05 \%$, and (d) $0.005 \%$.

Silk Nanofibers. It was clearly noted that the rheological properties of SF/FA solutions prepared from $0.005 \% \mathrm{Na}_{2} \mathrm{CO}_{3}$ concentration were dependent on concentrations according to Figure 3, showing that the viscosity of the regenerated silk solution rose with increasing the solution concentration as evidenced by previous reports $[5,8,9,13,14,16,19]$. However, the sample at concentration $3 \%$ showed a similar trend like samples degummed at $\mathrm{Na}_{2} \mathrm{CO}_{3}$ concentration $5 \%$ and $0.5 \%$ before and curves from samples at concentration $1 \%$ and $2 \%$ exhibited almost Newtonian fluid behavior (Figures $3(\mathrm{a}) \sim 3(\mathrm{c}))$. On the other side, the sample at concentration $6 \%$ behaved like the samples degummed at $\mathrm{Na}_{2} \mathrm{CO}_{3}$ concentrations $0.05 \%$ and $0.005 \%$ before, showing initial shearthickening behavior and then rapidly shear-thinning with shear rates acceleration (Figure 3(d)).

Following the measurement of viscosity, electrospinning of corresponding spinning solutions above was performed with the same experimental parameters (Figures 4 and 5). Surprisingly, amazing phenomenon happened regardless of the low viscosity close to that of the samples degummed at $\mathrm{Na}_{2} \mathrm{CO}_{3}$ concentrations $5 \%$ and $0.5 \%$. Instead of numerous beads, bead-on-string structural nanofibers from the $1 \%$ solution were formed with average diameter $27.0 \pm 6.8 \mathrm{~nm}$ (Figure $4(\mathrm{a})$ ). By increasing spinning concentration to $2 \%$,



FIGURE 3: Relationship between the shear viscosity and shear rate of the SF/FA solutions prepared from $0.005 \% \mathrm{Na}_{2} \mathrm{CO}_{3}$ concentration under different silk fibroin concentrations: (a) $1 \%$, (b) $2 \%$, (c) $3 \%$, and (d) $6 \%$. 


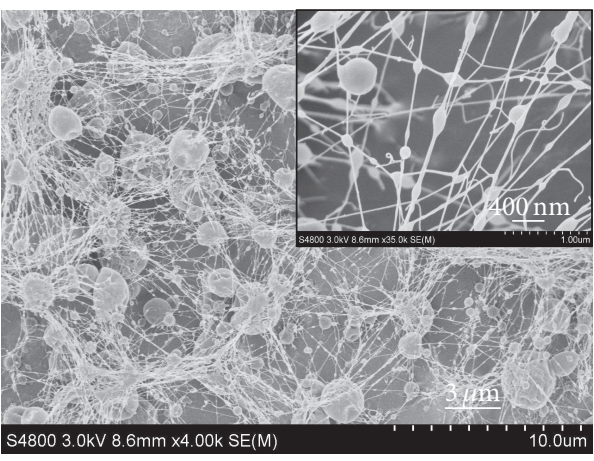

(a)

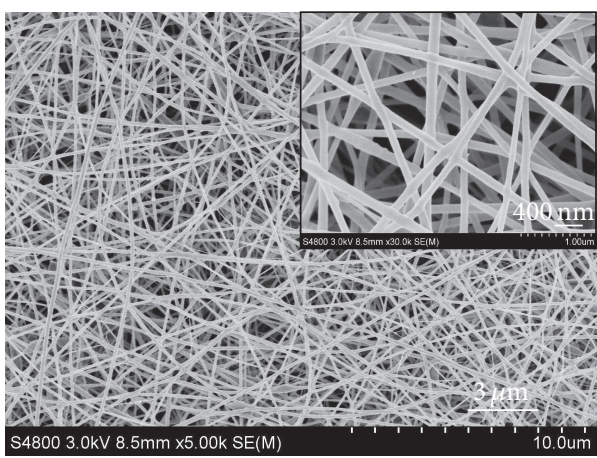

(c)

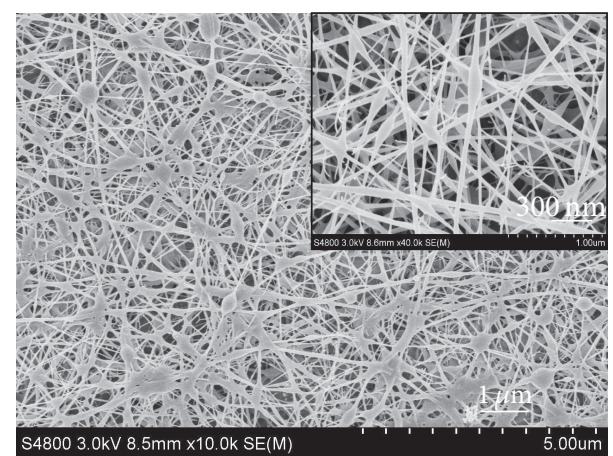

(b)

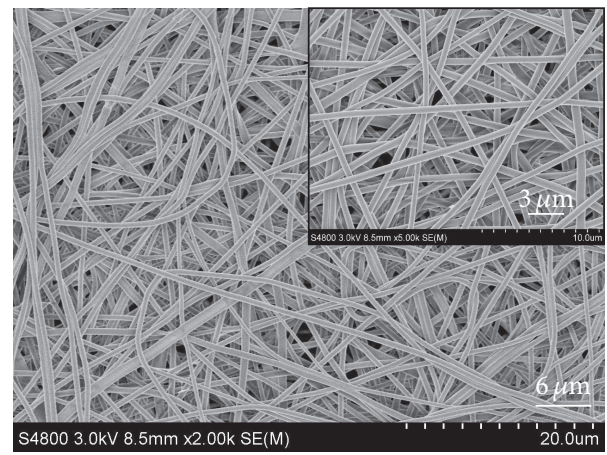

(d)

FIGURE 4: SEM images of electrospun silk nanofibers of the SF/FA solutions prepared from $0.005 \% \mathrm{Na}_{2} \mathrm{CO}_{3}$ concentration under different silk fibroin concentrations: (a) $1 \%$, (b) $2 \%$, (c) $3 \%$, and (d) $6 \%$.

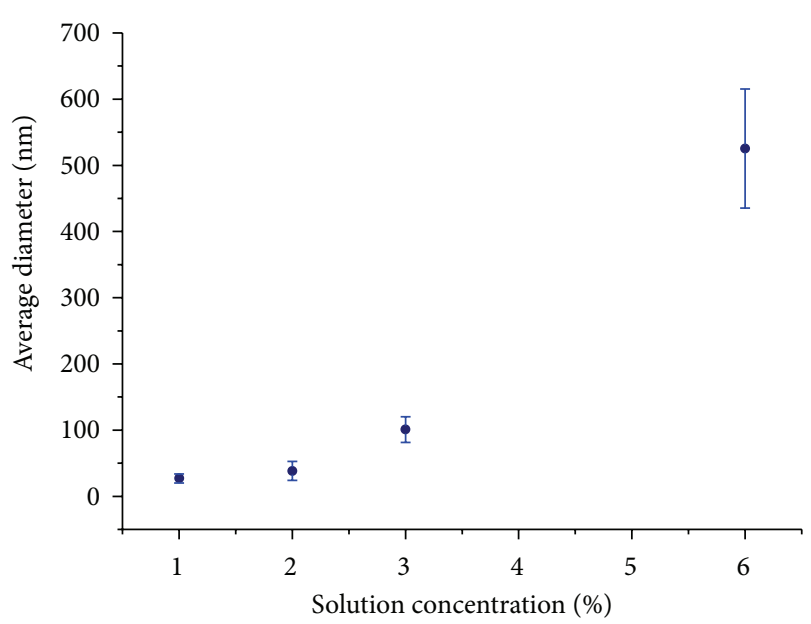

FIGURE 5: The relationship between average diameter of SF nanofibers and concentrations of SF/FA solutions derived from $0.005 \%$ $\mathrm{Na}_{2} \mathrm{CO}_{3}$ concentration.

beads diminished and spindle-shaped nanofibers appeared as shown in Figure 4(b). Furthermore, no beads but rod-like nanofibers were observed at the concentration of $3 \%$ with the average diameter $100.8 \pm 19.4 \mathrm{~nm}$ (Figure $4(\mathrm{c})$ ). Finally, more uniform silk nanofibers with larger diameter $525.4 \pm 90.1 \mathrm{~nm}$ were exhibited at higher concentration $6 \%$ (Figure $4(\mathrm{~d})$ ).

Comparing the electrospinning performance of the former solutions at $8 \%$ derived from $\mathrm{Na}_{2} \mathrm{CO}_{3}$ concentrations $5 \%$ and $0.5 \%$ with that of the four solutions mentioned above, it turned out to be completely different, despite the similar rheological behavior. Besides, the spinning solutions derived from $0.005 \% \mathrm{Na}_{2} \mathrm{CO}_{3}$ concentration could be successfully electrospun into continuous nanofibers with about $100 \mathrm{~nm}$ at such low viscosity with $3 \%$ spinning concentration. In order to account for the dramatical changes on the morphology of SF nanofibers and enhanced ability to electrospinning performance, understanding in microstructure intrinsic to different solutions from varied $\mathrm{Na}_{2} \mathrm{CO}_{3}$ concentrations is extremely important.

3.4. Effect of $\mathrm{Na}_{2} \mathrm{CO}_{3}$ Concentrations on the Microstructure of SF/FA Electrospinning Solutions. AFM images reflecting microstructural differences of spinning solutions obtained from different $\mathrm{Na}_{2} \mathrm{CO}_{3}$ concentrations were shown in Figure 6. As can be seen from Figure 6(a), numerous grainlike particles from the SF/FA solution with highest $\mathrm{Na}_{2} \mathrm{CO}_{3}$ concentration were observed with average diameter $38.5 \pm$ $16.6 \mathrm{~nm}$. A few particles aggregated as short arrays while most separated from each other. Morphology slightly changed when $\mathrm{Na}_{2} \mathrm{CO}_{3}$ concentration decreased to $0.5 \%$, as particles became bigger and irregular separately, from tens of nanometers to hundreds of nanometers (Figure 6(b)). Instead of nanoparticles, thin and short nanofibrils with few globules appeared by weakening $\mathrm{Na}_{2} \mathrm{CO}_{3}$ concentration to $0.05 \%$ and the width of an individual nanofibril was $52.4 \pm$ $16.4 \mathrm{~nm}$ (Figure 6(c)). Furthermore, a clear contrast to the 


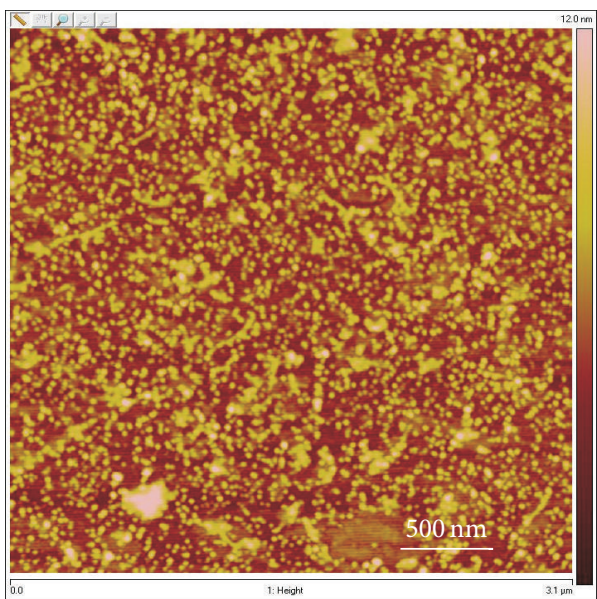

(a)

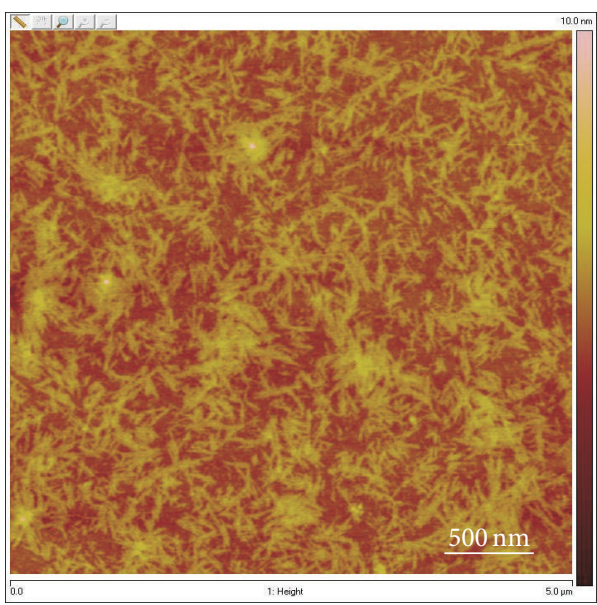

(c)

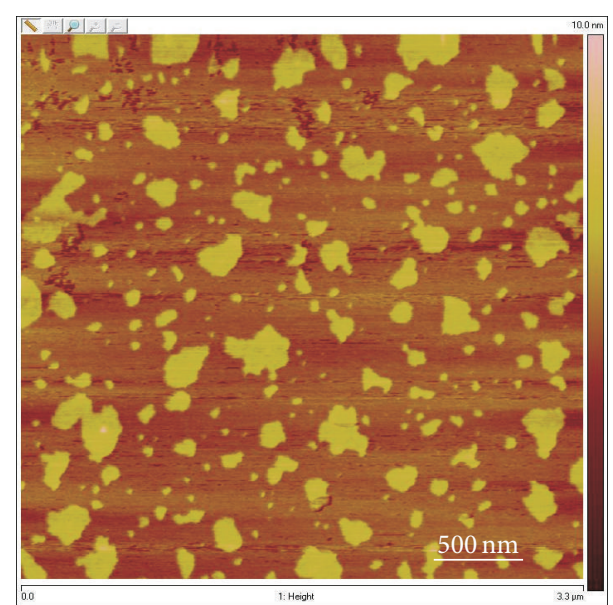

(b)

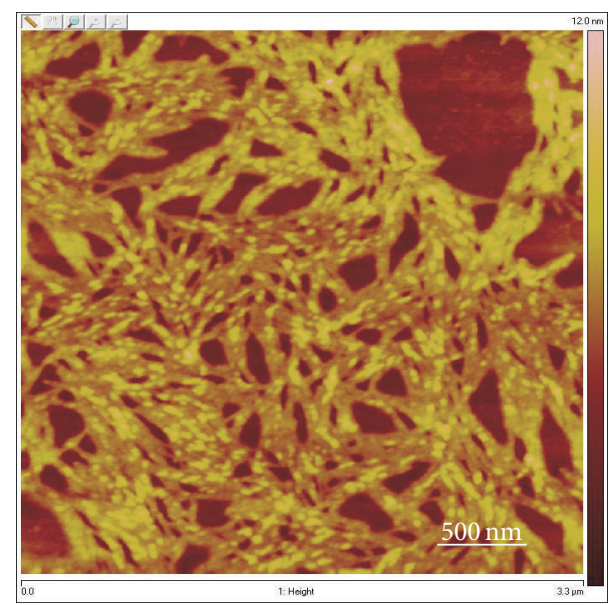

(d)

Figure 6: AFM images of the diluted SF/FA solutions with a concentration $0.0005 \mathrm{wt} \%$ prepared from different $\mathrm{Na}_{2} \mathrm{CO}_{3}$ conditions: (a) $5 \%$, (b) $0.5 \%$, (c) $0.05 \%$, and (d) $0.005 \%$.

previous three samples was exhibited in Figure 6(d), showing a network-like feature consisting of thick and densely packed nanofibrils with diameter of about $100 \mathrm{~nm}$. The observed difference in the morphology indicated direct relationship between $\mathrm{Na}_{2} \mathrm{CO}_{3}$ concentration and the microstructure in the SF/FA electrospinning solutions.

3.5. Effect of $\mathrm{Na}_{2} \mathrm{CO}_{3}$ Concentrations on the Microstructure of Aqueous SF Solutions. Since the regenerated SF films were prepared from aqueous SF solutions, it was necessary to investigate the microstructure of aqueous SF solutions which may be the source determining the microstructural types. According to the results in Figure 7, variations in not only structure but also size can be seen obviously. SF nanoparticles formed from $5 \% \mathrm{Na}_{2} \mathrm{CO}_{3}$ concentration were found alone with average diameter $71.0 \pm 12.0 \mathrm{~nm}$ and almost no connection between each other in Figure 7(a). SF nanoparticles become stretched like short nanorods by reducing $\mathrm{Na}_{2} \mathrm{CO}_{3}$ concentration to $0.5 \%$ (Figure $7(\mathrm{~b})$ ). Their size in length was $137.6 \pm 57.4 \mathrm{~nm}$ and width was $37.7 \pm 12.0 \mathrm{~nm}$, but SF nanorods were still separated. SF nanofibrils with fine diameter $70.4 \pm$
$17.3 \mathrm{~nm}$ appeared like random coil when decreasing $\mathrm{Na}_{2} \mathrm{CO}_{3}$ concentration to $0.05 \%$ as shown in Figure $7(\mathrm{c})$. Some of them got into large clusters while others were isolated. Further decrease of $\mathrm{Na}_{2} \mathrm{CO}_{3}$ concentration to $0.005 \%$ led to bigger SF clusters and the diameter of nanofibrils increased to $108.6 \pm 21.7 \mathrm{~nm}$. Moreover, branches of densely packed nanofibrils got together to form an interconnected structure (Figure 7(d)).

\section{Discussion}

Many studies have revealed that changes on the self-assembly behavior of silk fibroin at the nanoscale will make a difference to microstructural types of regenerated silks under various treatment conditions and microstructural types of silk fibroin play a key role in structure and properties of regenerated SF materials [19, 30-32]. Different self-assembly morphologies of four SF samples from aqueous solutions to spinning solutions in FA were demonstrated in Figures 7 and 6. Since excessive degumming conditions would disrupt the silk fibroin protein chains and generate smaller fragments, 




(a)

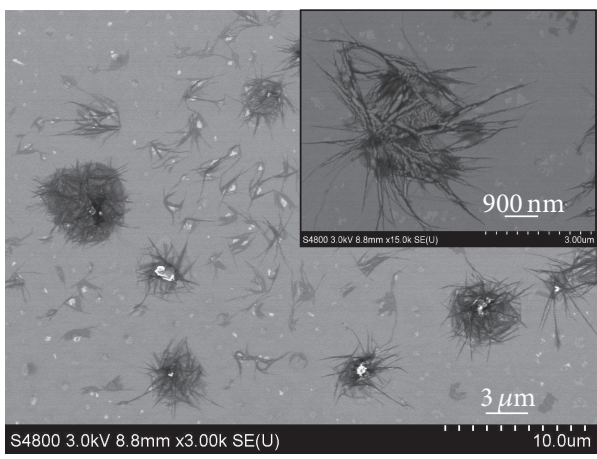

(c)

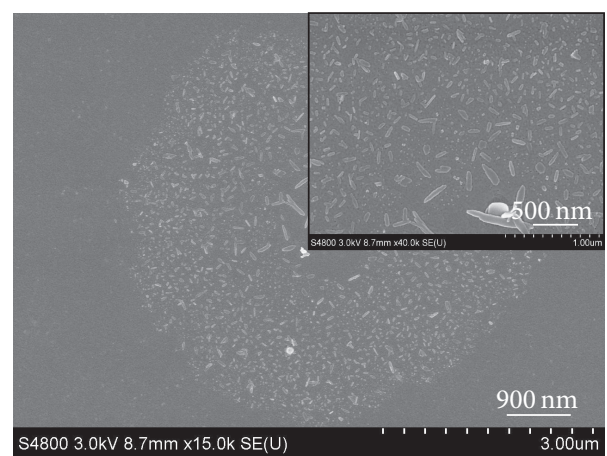

(b)

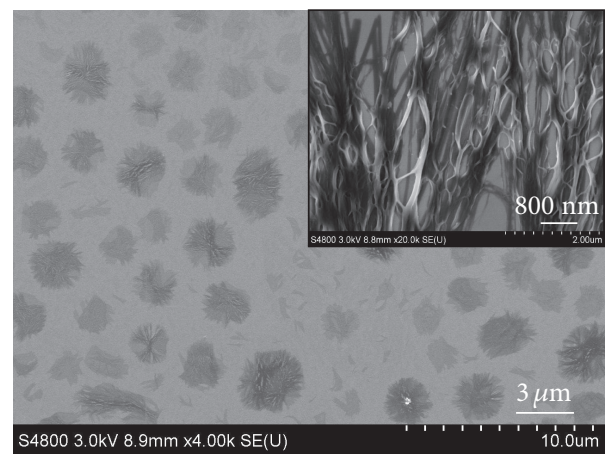

(d)

FIGURE 7: SEM images of the diluted SF aqueous solutions with a concentration $0.001 \mathrm{wt} \%$ prepared from different $\mathrm{Na}_{2} \mathrm{CO}_{3}$ conditions: (a) $5 \%$, (b) $0.5 \%$, (c) $0.05 \%$, and (d) $0.005 \%$.

resulting in failure to provide reproducible silk [21, 24]; nanoparticles were formed a lot from the SF/FA solutions with the $5 \%$ and $0.5 \% \mathrm{Na}_{2} \mathrm{CO}_{3}$ concentrations. In addition, these isolated nanoparticles are poorly efficient to entangle with neighbouring ones and stable in formic acid solution because formic acid provides carboxylic acids to generate interactions with polar side groups of SF small fragments which derive from amorphous linkers and $\mathrm{N}$ - and $\mathrm{C}$-terminal domains such as $\mathrm{CO}, \mathrm{OH}, \mathrm{COO}^{-}$, and $\mathrm{NH}_{3}^{+}[33,34]$. However, nanofibrils were found in the aqueous solutions and SF/FA solutions from the $0.05 \%$ and $0.005 \% \mathrm{Na}_{2} \mathrm{CO}_{3}$ concentrations. This is because low degumming concentration has so little damage on the degradation of silk molecular weight that long protein chains are originally reserved with different levels and easily aggregate into nanofibrils (Figures 7(c) and 7(d)).

From the standpoint of molecular mobility, differences on viscosity are associated with microstructural types. In Figure 1, the first shear-thickening behavior results from the entanglement of silk molecular and the difference that distinguishes the viscosity of solutions is that nanofibrils organized in more degree of entanglement than nanoparticles; then shear-thinning phenomenon of solutions from $0.05 \%$ and $0.005 \% \mathrm{Na}_{2} \mathrm{CO}_{3}$ concentrations was caused by the gradual orientation of nanofibrils with increasing shear rate while nanoparticles rapidly keep consistency in arrangement. Most importantly, diluting concentration at $1 \%, 2 \%$, and $3 \%$ solutions prepared from $0.005 \% \mathrm{Na}_{2} \mathrm{CO}_{3}$ concentration owns relatively short and less amount of nanofibrils which easily get uniform and oriented, showing Newtonian fluid behavior with relatively low viscosity (Figures 3(a) 3(c)).

Now a mechanism can be proposed to elucidate the relationship between $\mathrm{Na}_{2} \mathrm{CO}_{3}$ concentration and electrospinability as shown in Figure 8. Severe $\mathrm{Na}_{2} \mathrm{CO}_{3}$ concentration leads to the low molecular weight silk consisted of nanoparticles with weak interactions each other (Figures $7(a)$ and $7(b)$ ). After regenerated SF films are formed, these microstructural states are retained and accompanied in the following process. When electrostatic force is applied, droplets or beads are formed due to the strong stretch or breakup of the intrinsic nanoparticles in solutions. In contrast to that, nanofibrils exist in the high molecular weight silk solutions prepared from mild $\mathrm{Na}_{2} \mathrm{CO}_{3}$ concentration and permit extensive joints between the fibroin chains in the solution (Figures 7 (c) and $7(d))$. If higher voltages are applied, the entangled nanofibrils would move fast under powerful stretch and reassemble in the form of continuous nanofibers. In respect to the formation of silk nanofibers by electrospinning, nanofibrils formation is the foundation of spinnability and then certain spinning concentrations act as the necessary condition to obtain various morphologies and electrostatic force achieves the new assembly of nanofibers at last.

\section{Conclusion}

In this paper, regenerated SF/FA spinning solutions from different $\mathrm{Na}_{2} \mathrm{CO}_{3}$ concentrations were employed to produce 


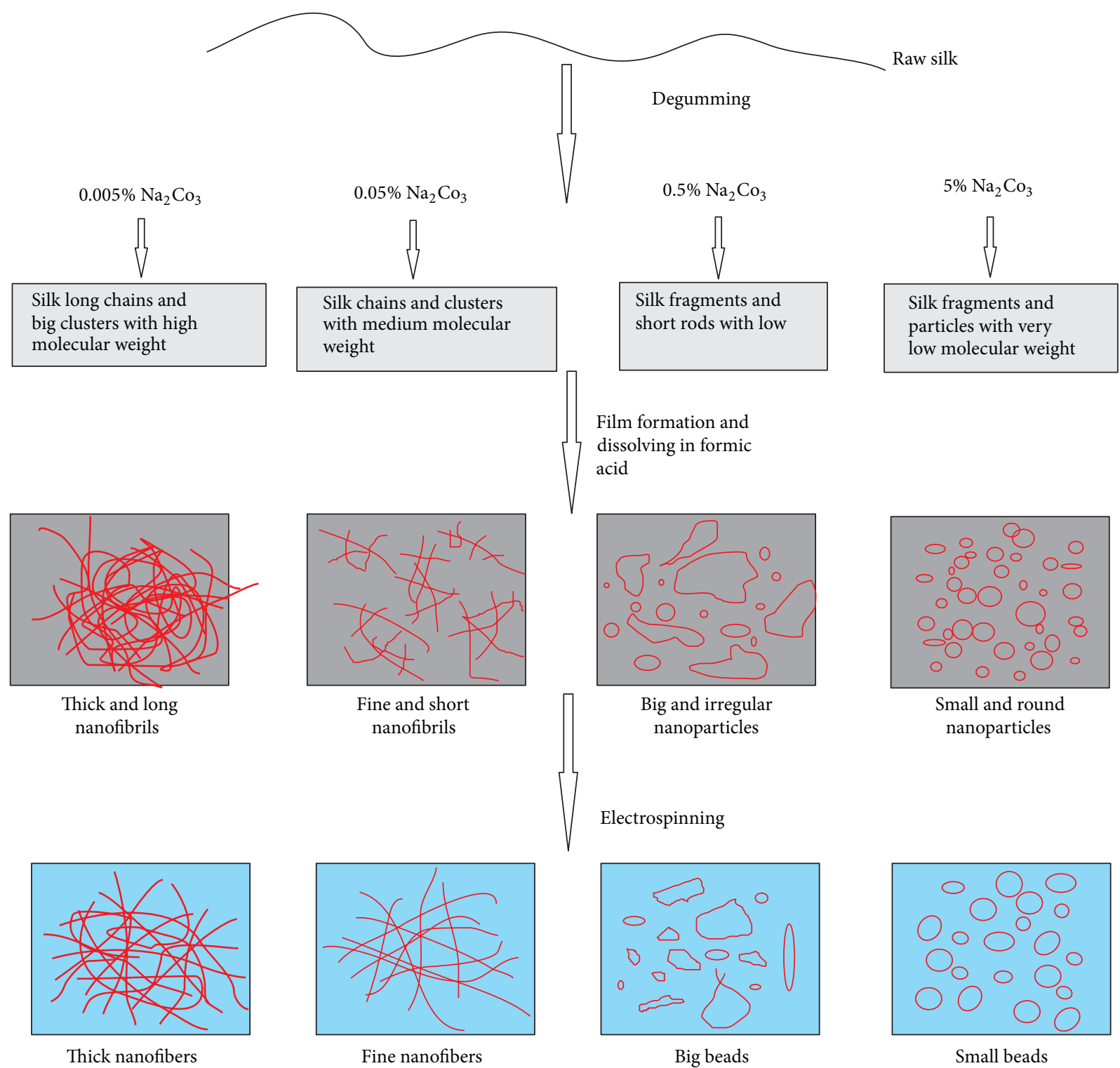

FIGURE 8: Schematic of the effect of $\mathrm{Na}_{2} \mathrm{CO}_{3}$ concentrations on the formation of regenerated SF nanofibers by electrospinning.

nanofibers by electrospinning and electrospun outcomes with various morphologies were observed, indicating that $\mathrm{Na}_{2} \mathrm{CO}_{3}$ concentration should be seriously considered during fabricating the SF nanofibers. Furthermore, microstructure types from the self-assembly of silk fibroin chains under different degraded degree by $\mathrm{Na}_{2} \mathrm{CO}_{3}$ become important factors which impact the efficiency and performance of silk electrospinning. Therefore, $\mathrm{Na}_{2} \mathrm{CO}_{3}$ concentration presents a new and effective control method to achieve the controllable sizes and morphologies of silk nanofibers.

\section{Conflict of Interests}

The authors declare that there is no conflict of interests regarding the publication of this paper.

\section{Acknowledgments}

This work was supported by the National Natural Science Foundation of China [81271723]; the Research and Innovation Project for College Graduates of Jiangsu Province [CXZZ13_0817]; and the Priority Academic Program Development of Jiangsu Higher Education Institutions (PAPD).

\section{References}

[1] C. Vepari and D. L. Kaplan, "Silk as a biomaterial," Progress in Polymer Science, vol. 32, no. 8-9, pp. 991-1007, 2007.

[2] Y. Wang, H. J. Kim, G. Vunjak-Novakovic, and D. L. Kaplan, "Stem cell-based tissue engineering with silk biomaterials," Biomaterials, vol. 27, no. 36, pp. 6064-6082, 2006. 
[3] A. Greiner and J. H. Wendorff, "Electrospinning: a fascinating method for the preparation of ultrathin fibers," Angewandte Chemie-International Edition, vol. 46, no. 30, pp. 5670-5703, 2007.

[4] S. Agarwal, A. Greiner, and J. H. Wendorff, "Functional materials by electrospinning of polymers," Progress in Polymer Science, vol. 38, no. 6, pp. 963-991, 2013.

[5] V. Pillay, C. Dott, Y. E. Choonara et al., "A review of the effect of processing variables on the fabrication of electrospun nanofibers for drug delivery applications," Journal of Nanomaterials, vol. 2013, Article ID 789289, 22 pages, 2013.

[6] X. Zhang, C. B. Baughman, and D. L. Kaplan, "In vitro evaluation of electrospun silk fibroin scaffolds for vascular cell growth," Biomaterials, vol. 29, no. 14, pp. 2217-2227, 2008.

[7] K. E. Park, S. Y. Jung, S. J. Lee, B. M. Min, and W. H. Park, "Biomimetic nanofibrous scaffolds: preparation and characterization of chitin/silk fibroin blend nanofibers," International Journal of Biological Macromolecules, vol. 38, no. 3-5, pp. 165173, 2006.

[8] B. M. Min, G. Lee, S. H. Kim, Y. S. Nam, T. S. Lee, and W. H. Park, "Electrospinning of silk fibroin nanofibers and its effect on the adhesion and spreading of normal human keratinocytes and fibroblasts in vitro," Biomaterials, vol. 25, no. 7-8, pp. 12891297, 2004.

[9] N. Amiraliyan, M. Nouri, and M. H. Kish, "Electrospinning of silk nanofibers. I. An investigation of nanofiber morphology and process optimization using response surface methodology," Fibers and Polymers, vol. 10, no. 2, pp. 167-176, 2009.

[10] B. Cramariuc, R. Cramariuc, R. Scarlet, L. R. Manea, I. G. Lupu, and O. Cramariuc, "Fiber diameter in electrospinning process," Journal of Electrostatics, vol. 71, no. 3, pp. 189-198, 2013.

[11] H. Jin, S. V. Fridrikh, G. C. Rutledge, and D. L. Kaplan, "Electrospinning Bombyx mori silk with poly(ethylene oxide)," Biomacromolecules, vol. 3, no. 6, pp. 1233-1239, 2002.

[12] W. H. Park, L. Jeong, D. I. Yoo, and S. Hudson, "Effect of chitosan on morphology and conformation of electrospun silk fibroin nanofibers," Polymer, vol. 45, no. 21, pp. 7151-7157, 2004.

[13] C. Chen, C. Chuanbao, M. Xilan, T. Yin, and Z. Hesun, "Preparation of non-woven mats from all-aqueous silk fibroin solution with electrospinning method," Polymer, vol. 47, no. 18, pp. 6322-6327, 2006.

[14] K. Ohgo, C. Zhao, M. Kobayashi, and T. Asakura, "Preparation of non-woven nanofibers of Bombyx mori silk, Samia cynthia ricini silk and recombinant hybrid silk with electrospinning method," Polymer, vol. 44, no. 3, pp. 841-846, 2002.

[15] F. Zhang, B. Q. Zuo, and L. Bai, "Study on the structure of SF fiber mats electrospun with HFIP and FA and cells behavior," Journal of Materials Science, vol. 44, no. 20, pp. 5682-5687, 2009.

[16] S. Sukigara, M. Gandhi, J. Ayutsede, M. Micklus, and F. Ko, "Regeneration of Bombyx mori silk by electrospinning-part 1: processing parameters and geometric properties," Polymer, vol. 44, no. 19, pp. 5721-5727, 2003.

[17] J. Ayutsede, M. Gandhi, S. Sukigara, M. Micklus, H. Chen, and F. Ko, "Regeneration of Bombyx mori silk by electrospinning. Part 3: characterization of electrospun nonwoven mat," Polymer, vol. 46, no. 5, pp. 1625-1634, 2005.

[18] S. Sukigara, M. Gandhi, J. Ayutsede, M. Micklus, and F. Ko, "Regeneration of Bombyx mori silk by electrospinning. Part 2. Process optimization and empirical modeling using response surface methodology," Polymer, vol. 45, no. 11, pp. 3701-3708, 2004.
[19] F. Zhang, B. Zuo, Z. Fan et al., "Mechanisms and control of silkbased electrospinning," Biomacromolecules, vol. 13, no. 3, pp. 798-804, 2012.

[20] H. J. Cho, C. S. Ki, H. Oh, K. H. Lee, and I. C. Um, "Molecular weight distribution and solution properties of silk fibroins with different dissolution conditions," International Journal of Biological Macromolecules, vol. 51, no. 3, pp. 336-341, 2012.

[21] E. M. Pritchard, X. Hu, V. Finley, C. K. Kuo, and D. L. Kaplan, "Effect of silk protein processing on drug delivery from silk films," Macromolecular Bioscience, vol. 13, no. 3, pp. 311-320, 2013.

[22] Q. Wang, Q. Chen, Y. Yang, and Z. Shao, "Effect of various dissolution systems on the molecular weight of regenerated silk fibroin," Biomacromolecules, vol. 14, no. 1, pp. 285-289, 2013.

[23] P. Jiang, H. Liu, C. Wang, L. Wu, J. Huang, and C. Guo, "Tensile behavior and morphology of differently degummed silkworm (Bombyx mori) cocoon silk fibres," Materials Letters, vol. 60, no. 7, pp. 919-925, 2006.

[24] L. S. Wray, X. Hu, J. Gallego et al., "Effect of processing on silkbased biomaterials: reproducibility and biocompatibility," Journal of Biomedical Materials Research B: Applied Biomaterials, vol. 99, no. 1, pp. 89-101, 2011.

[25] H. Yamada, H. Nakao, Y. Takasu, and K. Tsubouchi, "Preparation of undegraded native molecular fibroin solution from silkworm cocoons," Materials Science and Engineering C, vol. 14, no. 1, pp. 41-46, 2001.

[26] S. Zarkoob, R. K. Eby, D. H. Reneker, S. D. Hudson, D. Ertley, and W. W. Adams, "Structure and morphology of electrospun silk nanofibers," Polymer, vol. 45, no. 11, pp. 3973-3977, 2004.

[27] J. S. Ko, K. Yoon, C. S. Ki et al., "Effect of degumming condition on the solution properties and electrospinnablity of regenerated silk solution," International Journal of Biological Macromolecules, vol. 55, pp. 161-168, 2013.

[28] M. Moriya, F. Roschzttardtz, Y. Nakahara, H. Saito, Y. Masubuchi, and T. Asakura, "Rheological properties of native silk fibroins from domestic and wild silkworms, and flow analysis in each spinneret by a finite element method," Biomacromolecules, vol. 10, no. 4, pp. 929-935, 2009.

[29] C. Holland, A. E. Terry, D. Porter, and F. Vollrath, "Comparing the rheology of native spider and silkworm spinning dope," Nature Materials, vol. 5, no. 11, pp. 870-874, 2006.

[30] S. Putthanarat, S. Zarkoob, J. Magoshi et al., "Effect of processing temperature on the morphology of silk membranes," Polymer, vol. 43, no. 12, pp. 3405-3413, 2002.

[31] Q. Lu, H. Zhu, C. Zhang, F. Zhang, B. Zhang, and D. L. Kaplan, "Silk self-assembly mechanisms and control from thermodynamics to kinetics," Biomacromolecules, vol. 13, no. 3, pp. 826832, 2012.

[32] I. Greving, M. Cai, F. Vollrath, and H. C. Schniepp, "Shearinduced self-assembly of native silk proteins into fibrils studied by atomic force microscopy," Biomacromolecules, vol. 13, no. 3, pp. 676-682, 2012.

[33] I. C. Um, H. Y. Kweon, K. G. Lee, and Y. H. Park, “The role of formic acid in solution stability and crystallization of silk protein polymer," International Journal of Biological Macromolecules, vol. 33, no. 4-5, pp. 203-213, 2003.

[34] I. C. Um, H. Kweon, Y. H. Park, and S. Hudson, "Structural characteristics and properties of the regenerated silk fibroin prepared from formic acid," International Journal of Biological Macromolecules, vol. 29, no. 2, pp. 91-97, 2001. 

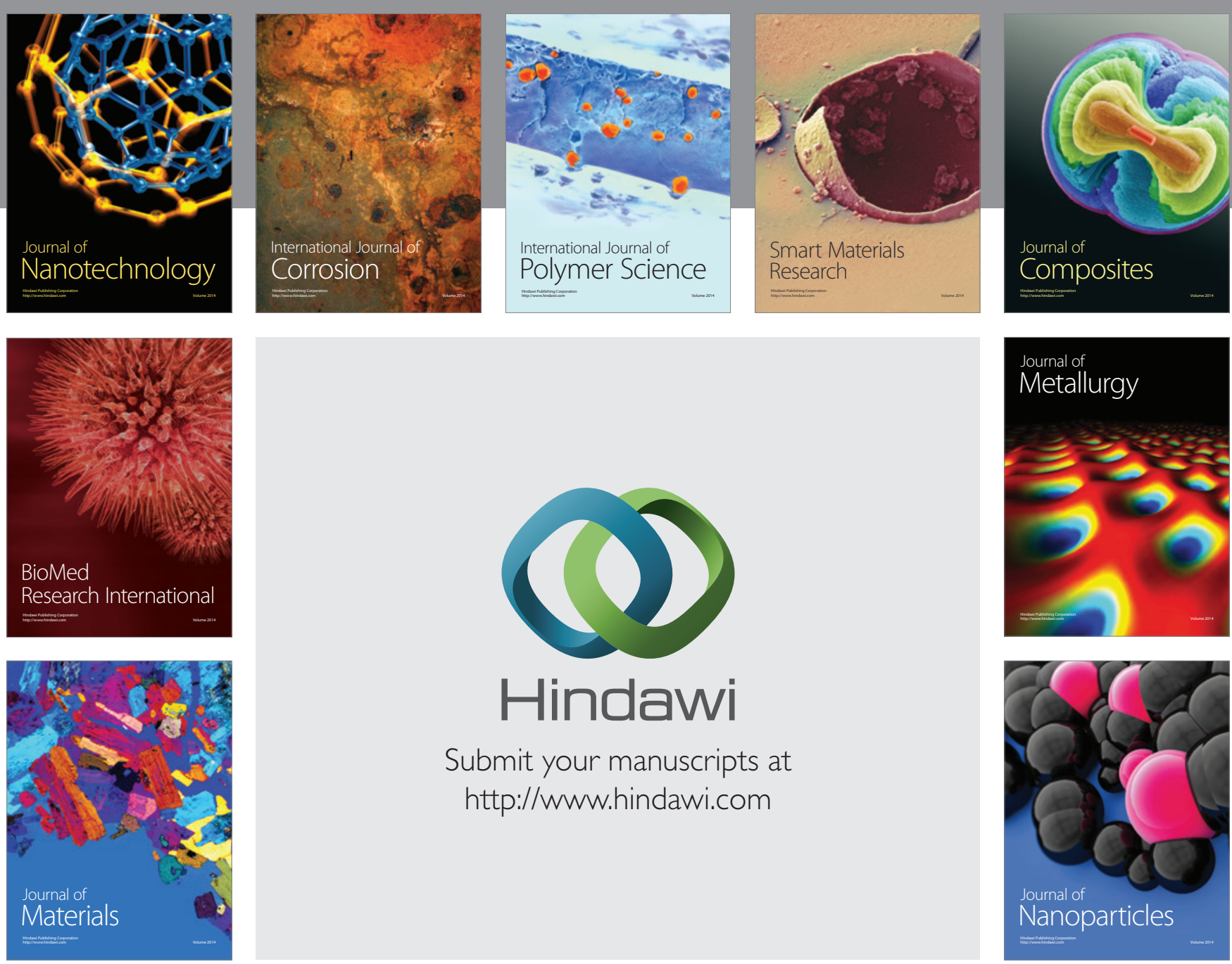

Submit your manuscripts at http://www.hindawi.com
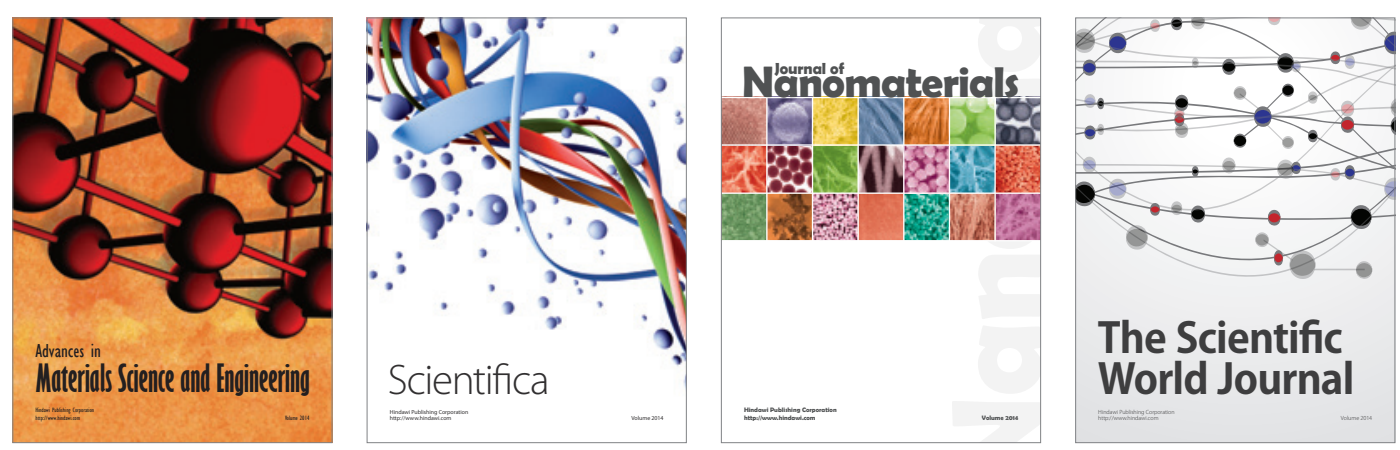

\section{The Scientific World Journal}
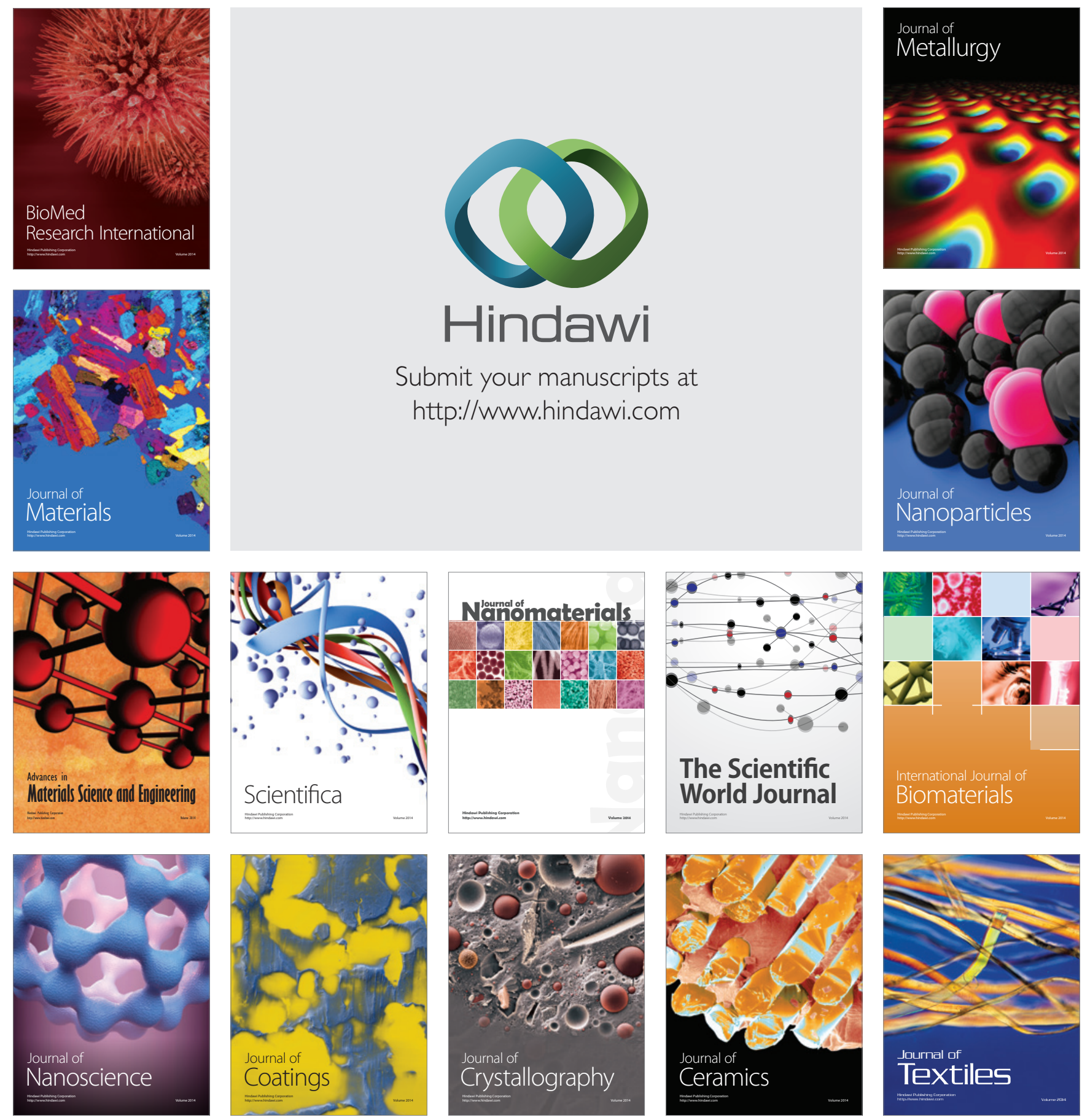